Journal of Trauma and Dissociation, 18(4):490-506, 2017

\title{
Depersonalization and Derealization in Self-Report and Clinical Interview: The Spectrum of Borderline Personality Disorder, Dissociative Disorders , and Healthy Controls
}

\author{
Vedat Şar, MD, Firdevs Alioğlu, MD, Gamze Akyüz, MD
}

\begin{abstract}
Depersonalization and derealization were examined among college students with and without borderline personality disorder (BPD) and/or dissociative disorders (DDs) by self-report and clinician assessment. The Steinberg Depersonalization and Derealization Questionnaires (SDEPQ and SDERQ), the Childhood Trauma Questionnaire, and the screening tool of the BPD section of the Structured Clinical Interview for DSM-IV (SCID-BPD) were administered to 1301 students. Those with BPD ( $\mathrm{n}=80$ ) according to the SCID-BPD and 111 non-BPD controls were evaluated using the Structured Clinical Interview for DSM-IV Dissociative Disorders (SCID-D) by a psychiatrist blind to the diagnosis. Test-retest evaluations and internal consistency analyses suggested that SDEPQ and SDERQ were reliable instruments. Of the participants, 19.7\% reported SDEPQ (17.8\%) and/or SDERQ (11.0\%) scores above cut-off levels and impairment by these experiences. Principle component analysis of 26 items of both scales yielded four factors: cognitiveemotional, perceptual, and bodily detachment, and detachment from reality. Participants with concurrent DD and BPD had the highest scores of depersonalization and derealization in clinical interview and self-report. While BPD was associated with the severity of childhood trauma and
\end{abstract}


dissociation, derealization rather than depersonalization had a special relation to BPD. The experience of "detachment from reality" may differentiate BPD from DD.

Key Words: Depersonalization, derealization, self-report, borderline personality disorder

Notwithstanding diversity of opinions about their dissociative nature, depersonalization (DEP) and derealization (DER) have been considered among basic dimensions of dissociative psychopathology by many authors (Spiegel et al., 2011). They have been combined to "DEPDER disorder" and placed into the dissociative disorders (DDs) section in DSM-5 (American Psychiatric Association, 2013). Beside all specific DDs, both DEP and DER can occur in a variety of psychiatric syndromes from anxiety to schizophrenic disorders, and even in healthy individuals. For instance, a dissociative subtype of PTSD has been defined by the additional symptoms of DEP and/or DER (Lanius et al., 2010). This stance has been challenged on the ground that dissociation was not limited to "negative" symptoms and restricted consciousness only (Dorahy and Van der Hart, 2015). In fact, representing a wide spectrum, dissociation may also result in "positive" symptoms such as flashbacks which have a rather intrusive quality as seen in PTSD which does not fit the dissociative subtype as defined by DSM-5. Moreover, dissociation may disrupt sensori-motor functions to create functional neurological symptoms such as pseudoseizures.

According to the DSM-5, individuals with borderline personality disorder (BPD) may also have transient dissociative symptoms including DEP and/or DER. However, taken both the "positive" and "negative" symptoms into account, dissociative phenomena exceed these limits 
in a significant majority of the individuals who fit the DSM-5 diagnostic criteria of BPD (Sar et al., 2003; Sar, Akyuz, Kugu, Ozturk, \& Ertem-Vehid, 2006). Those people warrant dual diagnosis; i.e. DD and BPD, concurrently. Both disorders are characterized by high prevalence of reported childhood abuse and/or neglect, disturbed attachment, and affect dysregulation (Sar et al., 2003; Sar, Akyuz, Kugu, Ozturk, \& Ertem-Vehid, 2006; Simeon, Guralnik, Schmeidler, Sirof, \& Knutelska, 2001; Van Dijke et al., 2010, Van Dijke and Ford,2015). Given these commonalities, it is unclear whether this spectrum of psychopathopathology represents a posttraumatic dissociative disorder or a personality disorder or both (Meares, 2012; Sar, 2011).

The concept of trauma covers both the noxious agent and the perception and response of the affected subject. Hence, Fischer and Riedesser (1999) defined psychological trauma in its objective and subjective aspects as the vital discrepancy between severity of the stressful event and the ability of the individual to cope with it. Possible discrepancies in subjective experiencing and objective assessment of the trauma-generated psychopathology have scarcely been subject to empirical investigation. Indeed, two previous studies conducted on individuals with BPD and DDs (Edell, Joy, \& Yehuda ,1990; Şar, Alioğlu, Akyüz, \& Karabulut, 2014) suggested a relationship of such discrepancies to the psychopathology itself; i.e. impact of intrapsychic and interpersonal fears on the patient's subjective experience and the ability to express them. Namely, individuals with BPD and/or DDs suffer from elevated interpersonal sensitivity due to their traumatic antecedents. DEP and DER constitute a particular target of inquiry because they are related to subjective detachment of the individual from oneself and/or environment possibly regulating the avoidance of internal and external threats.

In the present study, we first inquired into the psychometric features of two self-report measures of DEP and DER. Second, we attempted to gather data about the prevalence of both 
phenomena in a highly functional non-clinical population. Third, we tried to evaluate experiences of DEP and DER in a subsample of, respectively, individuals with DDs and/or BPD and those with none of them. This was in order to identify the discriminative power of DEP and DER on two significantly overlapping syndromes of the spectrum of trauma-related psychopathology. Fourth, we tried to demonstrate the systematic discrepancies between selfreport and clinician-administered assessment of DEP and DER on this spectrum characterized by internal and interpersonal fears alongside an inquiry into the potential correlates of possible discrepancies. Finally, we tried to identify clues about the nature of the relationship between BPD and DDs in the context of DEP and DER experiences and their developmental and clinical correlates.

\section{METHOD}

The full methodology of this study has been reported in two previous papers (Sar, Akyuz, Kugu, Ozturk, \& Ertem-Vehid, 2006; Şar, Alioğlu, Akyüz, \& Karabulut, 2014) which addressed different questions (e.g. childhood trauma and dissociative amnesia) concerning the relationship between BPD and DDs.

\section{Participants}

Among all students of the Cumhuriyet University in Sivas (Turkey), 1301 participants (10\% of the student population) were randomly selected (554 women, 42.6\%). Participants provided written informed consent following explanation of the study procedures. The study was approved by the Academic Council of the Sivas University Department of Psychiatry.

\section{Instruments}

1. The Steinberg Dissociation Questionnaires: These are five self-rating scales which 
evaluate the severity of dissociative amnesia (DA), DEP, DER, identity confusion, and identity alteration (Steinberg \& Schnall, 2000). A score between 1 and 5 is assigned to each item. Item scores are added up to total scores for each of the five scales. The Steinberg Depersonalization Questionnaire (SDEPQ) consists of 15 items with a total score of 14-70. One "normal" item which is placed among pathological items does not contribute to the total score. The Steinberg Derealization Questionnaire (SDERQ) consists of 12 items with a total score of12-60. Both scales have three additional questions which inquire into the distress and dysfunctionality caused by the symptoms. The unpublished translation by Vedat Sar has been utilized in this study.

2. The Structured Clinical Interview for DSM-IV Dissociative Disorders (SCID-D) is a semi-structured interview developed by Steinberg (1994). Turkish version of the instrument is as valid and reliable as the original form (Kundakci, Şar, Kiziltan, Yargic, \&Tutkun, 2014).

3. The Structured Clinical Interview for DSM-IV Personality Disorders (SCID-II) is a semi-structured interview (First, Gibbon, Spitzer, Williams, \& Benjamin,1996). The self-report version was utilized for the initial screening. The Turkish version of the SCID-II had an interrater reliability of 0.95 (kappa) for BPD (Coskunol, Bagdiken, Sorias, \& Saygili, 1994).

4. The Childhood Trauma Questionnaire (CTQ) is a 28-item self-report instrument (Bernstein et al., 1994). Possible scores for each type of childhood trauma range from 1 to 5 with a total score ranging from 5 to 25 . There is also a minimization/denial of trauma score with a range of 0 to 3 . The Turkish version of the scale is as valid as its original form (Sar, Ozturk,\& Ikikardes, 2012).

\section{Procedure}

This study was originally planned to inquire into the DD comorbidity of BPD (Sar, Akyuz, 
Kugu, Ozturk, \& Ertem-Vehid, 2006). After screening with the self-rating tools of the SCID-BPD, CTQ and Steinberg Dissociation Questionnaires, the semi-structured SCID-BPD was administered to those participants who had probable BPD at the initial assessment. The SCID-D was administered both to those with BPD and to a control group without BPD randomly selected from the same population.

\section{RESULTS}

\section{Characteristics of the Participants}

The mean age $(\mathrm{N}=1301)$ was $20.6(\mathrm{SD}=1.7$ range $=18-29)$. When evaluated in the second phase of the study ( $\mathrm{n}=191$ ), 100 students (42 women, 42.0\%) had either BPD and/or DD. In the DDs group ( $n=78), 42$ participants had DD not otherwise specified. The remaining had DA $(n=15)$, DEP disorder $(n=12)$, or DID $(n=9)$. Twenty-two participants (7 women, $31.8 \%)$

constituted the "BPD only" group. Those with neither DD nor BPD (n=91) served as controls (34 women, $37.4 \%$ ). There was no significant difference in gender distribution between the four groups (double diagnosis, BPD only, DD only, and controls) $\left(\chi^{2}=4.13, d f=3, p=0.248\right)$.

There were weak but significant correlations (Spierman) between age and SDERQ (rho = $0.08, \mathrm{p}=0.005)$ but not SDEPQ $(\mathrm{rho}=0.05, \mathrm{p}=0.079)(\mathrm{N}=1301)$. Economic status was negatively correlated with SDEPQ (rho $=-0.07, \mathrm{p}=0.013$ ) but not with SDERQ (rho $=-0.05, \mathrm{p}=0.086$ ). SDEPQ did not differ between men $(M=18.1, S D=7.2)$ and women $(M=17.9, S D=6.5)$ (Kruskal-Wallis $\mathrm{p}=0.077)$. Women $(\mathrm{M}=24.5, \mathrm{SD}=7.4)$ did not differ from men $(\mathrm{M}=24.0, \mathrm{SD}=$ 7.7) (Kruskal-Wallis $\mathrm{p}=0.697$ ) on SDERQ either. Overall, demographic factors were not relevant to the findings except the SDEPQ score for economic status.

\section{Analysis of Reliability}


The total score and item-corrected correlations were between 0.49- 0.67 for SDEPQ and 0.56 - 0.72 for SDERQ $(\mathrm{N}=1301)$. In the DD group, they were $0.20-0.77$ for SDEPQ and $0.61-0.82$ for SDERQ. Cronbach's alpha coefficients were 0.88 for SDEPQ and 0.91 for SDERQ (N=1301). For the DD group, they were 0.91 and 0.90 , respectively. Gutmann's split-half scores were 0.86 for SDEPQ and 0.88 for SDERQ $(\mathrm{N}=1301)$, and 0.87 and 0.89 in the DD group, respectively. These values indicated that both scales were internally consistent measures. Test-retest reliability was calculated using Pearson correlations from scale scores of 19 dissociative patients who completed the scales on two occasions separated by an average interval of 37.6 days $(\mathrm{SD}=28.0$, range $=7-112$ ). For the total scores, the overall test-retest correlations were $r=0.89$ and $r=0.92$ for SDEPQ and SDERQ, respectively ( $\mathrm{p}<0.001$ for both of them). Thus, these scores were stable over an interval of approximately eight weeks on average.

\section{Analysis of Concurrent Validity}

Validity analyses were conducted on the subset of participants $(n=191)$ whose diagnostic statuses were available; i.e. those who were examined by both the SCID-D and SCID-BPD in addition to the self-report measures.

Comparison with Other Measures: Using the Kruskal-Wallis analysis, participants with DD had significantly higher SCID-D DEP $(\mathrm{M}=2.4 \mathrm{SD}=1.0$ versus $\mathrm{M}=1.0 \mathrm{SD}=0.0)$, and SCID-D $\operatorname{DER}(\mathrm{M}=1.5 \mathrm{SD}=0.9$ versus $\mathrm{M}=1.0 \mathrm{SD}=0.0)$ scores than non-DD controls. Participants with (M $=32.4 \mathrm{SD}=9.7)$ and without $\mathrm{DD}(\mathrm{M}=24.2 \mathrm{SD}=6.6)$ differed significantly on both scores $(\mathrm{M}$ $=25.6 \mathrm{SD}=10.2$ versus $\mathrm{M}=17.6 \mathrm{SD}=5.5)$, respectively. SDEPQ and SDERQ scores were correlated with each other, SCID-D total and SCID-D DA, and Steinberg self-rating DA (SDAQ) 
(Table 3), and identity alteration (SIAQ) scores (rho=0.83 and 0.81$)$, respectively. $(\mathrm{p}=0.001$ for all analyses).

Cut-off Score of SDEPQ: Taking a SDEPQ score of 29 and above as the cut-off point and on the condition that at least one type of psychosocial impairment (relationship with friends, family, and coworkers, ability to work, or discomfort or distress) is reported by the subject, sensitivity of the SDEPQ was $61.7 \%$ and specificity was $77.1 \%$ in differentiating the participants with moderate to severe DEP ( $n=47)$ in SCID-D (scores 3 or 4 ) from those with no or mild DEP ( $\mathrm{n}=144)$ (scores 1 or 2$)$. In the Kruskal-Wallis analysis, comparison between two groups yielded a significant difference on SDEPQ $(\mathrm{M}=34.7 \mathrm{SD}=9.7$ versus $\mathrm{M}=25.2 \mathrm{SD}=7.4$, respectively). Comparison between 71 participants who had a SDEPQ score of 29 or above and 120 participants with a score of below 29 yielded a significant difference on SCID-D DEP scores $(\mathrm{M}=2.0 \mathrm{SD}=1.1$ versus $\mathrm{M}=1.3 \mathrm{SD}=0.7)(\mathrm{p}=0.001$ for all analyses $)$.

Cut-off Score of SDERQ: Taking a SDERQ score of 26 and above as the cut-off point and on the condition that at least one type of psychosocial impairment was reported by the subject, sensitivity of SDERQ was $66.7 \%$ and specificity was $80.2 \%$ in differentiating the participants with moderate to severe DER in SCID-D $(n=15)$ from those with no or mild DER $(n=176)$. In the Kruskal-Wallis analysis, comparison between two groups yielded a significant difference on SDERQ ( $M=29.5 \mathrm{SD}=9.2$ versus $\mathrm{M}=20.1 \mathrm{SD}=8.3$, respectively). A comparison between 46 participants who had a SDERQ score of 26 or above and 145 participants with a score of below 26 yielded a significant difference on $\mathrm{SCID}-\mathrm{D}$ DER ( $\mathrm{M}=1.5 \mathrm{SD}=0.9$ versus $\mathrm{M}=1.1 \mathrm{SD}=0.4)$. $(\mathrm{p}=0.001$ for all analyses $)$.

\section{Distribution of Depersonalization and Derealization Scores}


Of the overall study group, $19.7 \%(n=256)$ had SDEPQ and/or SDERQ scores above the cuf-off levels (29 and 26 or above, respectively) and some impairment. Table 1 shows the average scores and prevalences of SDEPQ and SDERQ items. "Feeling spacey" scored highest and showed the widest prevalence.

DEP Scores: Sixty-nine participants (5.3\%) had a SDEPQ total score of 14. Among all participants, 927 had (71.3\%) 15-28, 281 (21.6\%) had 29-44, and 24 (1.8\%) had 45 or higher. Of the participants, $468(36 \%)$ reported distress from y their symptoms either due to social impairment ( $\mathrm{n}=263,20.2 \%)$, loss of working capacity $(\mathrm{n}=301,23.1 \%)$, or subjective distress $(\mathrm{n}=383,29.4 \%)$. Taking the participants who had a SDEPQ score above the cut-off level (29 or higher) and had some type of impairment, 232 (17.8\% of the overall study group) had remarkable DEP.

DER scores: Of all participants, $287(22.1 \%)$ had a SDERQ total score of 12,835 had (64.2\%) 13 to 25,163 (12.5\%) had 26 to 40, and 16 (1.2\%) had 41 or higher. Among participants, $375(28.8 \%)$ reported that they were distressed by their symptoms either due to social impairment $(n=237,18.2 \%)$, loss of working capacity $(n=231,17.8 \%)$, or subjective distress $(n=314,24.1 \%)$. Considering that those with a SDERQ score of 26 or above who had some type of impairment, $11.0 \%(n=143)$ of the overall study group had remarkable DER.

\section{Factor Analysis of Depersonalization-Derealization Experiences}

A principal component analysis with varimax rotation was conducted on 26 items of the two scales using the data gathered from participants $(n=191)$ who engaged in diagnostic interviews. Four dimensions were recruited that had eigenvalues above 1 . These explained 60.2 $\%$ of the total variance (see Table 2). The largest factor represented cognitive-emotional self- 
detachment. The remaining three factors represented perceptual detachment, detachment from reality, and bodily self-detachment. Factor scores of these four components were computed and saved to enter into correlational analyses with other variables (see Table 3).

\section{Depersonalization-Derealization and Childhood Trauma}

There were modest correlations between SDEPQ or SDERQ and CTQ total scores in the study group (rho $=0.42$ and 0.38 ) overall and moderate correlations in the DD group (rho $=0.45$ and $\mathrm{r}=0.39$ ), respectively ( $\mathrm{p}=0.001$ for all analyses). In stepwise regression analysis taking five types of childhood trauma as independent variables $(\mathrm{N}=1301)$, emotional abuse $(\mathrm{B}=6.16 \mathrm{p}=0.001)$, physical neglect $(\mathrm{B}=3.27 \mathrm{p}=0.001)$, and sexual abuse $(\mathrm{B}=1.86 \mathrm{p}=0.003)$ predicted SDEPQ total score $(\mathrm{F}=83.28, \mathrm{df}=1297,3, \mathrm{p}=0.001)$. The same variables predicted SDERQ score: Emotional abuse $(B=5.33 p=0.001)$, physical neglect $(B=2.90 p=0.001)$, and sexual abuse $(B=1.22 p=0.035)$ $(\mathrm{F}=70.98, \mathrm{df}=1297,3)$. These data supported the convergent validity of SDEPQ and SDERQ.

\section{Borderline Personality Disorder and Dissociation}

There were significant correlations between total number of the DSM-IV BPD criteria met and all self-report and clinician-based dissociation measures (Table 3). The BPD group had higher SCID-D total $(\mathrm{M}=8.53, \mathrm{SD}=3.23)$, SCID-D DEP $(\mathrm{M}=2.05, \mathrm{SD}=1.08)$ and SCID-D

DER $(M=1.41 \quad \mathrm{SD}=0.84)$ scores than those without $\mathrm{BPD}(\mathrm{M}=5.47, \mathrm{SD}=1.41 ; \mathrm{M}=1.20, \mathrm{SD}=$ $0.57 ; \mathrm{M}=1.02, \mathrm{SD}=0.19)$, respectively. They also had higher SDEPQ $(\mathrm{M}=32.95, \mathrm{SD}=9.47)$ and SDERQ $(\mathrm{M}=26.16, \mathrm{SD}=9.82)$ scores than those without $\mathrm{BPD}(\mathrm{M}=23.64, \mathrm{SD}=6.18 ; \mathrm{M}=$ 17.06, $\mathrm{SD}=5.16$ ), respectively (Kruskal-Wallis analysis, $\mathrm{p}=0.001$ for all comparisons). These findings suggestthat $B P D$ is associated with severity of dissociation and vice versa. 
Table 4 shows comparison of scale scores according to DD or BPD status (BPD+DD, BPD only, DD only, Controls). There were significant differences between the four groups on all measures except self-reported "perceptual detachment" and "bodily self-detachment". Post hoc analysis (Tukey test) confirmed that the BPD+DD ("dual diagnosis") group obtained significantly higher scores than the remaining on all scales with one exception: SCID-D DEP did not differentiate dual diagnosis from the "DD only" group. Like DD, BPD had a significant effect on SCID-D DER. However, BPD had no significant effect on SCID-D DEP while the DD did. While both disorders had significant effect on "cognitive-emotional self-detachment", unlike DDs, BPD had significant effect on "detachment from reality" as well. Hence, BPD differs from DDs by (self report) “detachment from reality”, while DDs differs from BPD on DEP (in clinical interview).

Only the SCID-D total score differentiated "BPD only" from "DD only" groups (with a higher mean score for the latter). While none of the SCID-D scores differentiated the "BPD only" group from those without BPD or DD ("controls"), both SDEPQ and SDERQ did so. The SCID-D total and SCID-D DEP scores differentiated "DD only" group from "controls". Hence, at the milder end of the spectrum, SCID-D DEP and total scores were more effective in detecting $D D$, while self-report instruments (SDEPQ and SDERQ) did so for BPD.

Significant statistical interaction between BPD and DDs were observed for SCID-D DER and total scores as well as the "detachment from reality" factor. All SCID-D scores and “detachment from reality” factor were correlated with BPD criteria. Both SCID-D DER and "detachment from reality" factor were associated with severity of the condition (the spectrum of DD and/or BPD). SCID-D DER was correlated with SCID-DA but not with self-reported DA; 
however, the opposit was valid for self-reported DER. Hence, "awareness" of DER and DA behave in tandem.

Neither BPD nor DD had any significant effect on bodily self-detachment and perceptual detachment (Table 4). Perceptual detachment was correlated with DA, SCID-D DEP, and criteria of BPD but not with SCID-D DER and total scores (Table 3). Bodily self-detachment was also correlated with self-reported DA but not with any SCID-D score and BPD criteria. Hence, perceptual detachment and bodily self-detachment were related to DA but not to the severity of the overall condition.

\section{Childhood Trauma, Dissociation, and Borderline Personality Disorder}

Total number of endorsed BPD criteria had significant correlations with all types of childhood trauma. Hence, the proposed association between criteria of BPD and overall severity of the psychopathological condition (i.e. BPD and/or DD) was supported by childhood trauma histories as well. CTQ total score was correlated with all four factors derived from selfassessment (cognitive-emotional self-detachment, perceptual detachment, detachment from reality, and bodily self-detachment) and with SCID-D scores except SCID-D DER (Table 3). Hence, association of SCID-D DER with BPD was independent of a childhood trauma history or, alternatively, these participants with elevated SCID-D DER underreported their childhood traumata as they did for their DA. While bodily self-detachment was correlated with physical and emotional neglect, perceptual detachment was related to diverse types of childhood trauma (Table 3). Being correlated with each other, criteria of BPD and perceptual detachment shared the common feature of a multiple childhood trauma rather than neglect history.

\section{DISCUSSION}

The good internal consistency and test-retest correlations of the study suggest that the 
SDEPQ and SDERQ are reliable instruments. Total scores of 29 and 26 and above appeared as the best cut off levels for SDEPQ and SDERQ, respectively. Of the overall sample, 17.8\% had SDEPQ and $11.0 \%$ SDERQ scores above cut-off alongside psychosocial impairment; i.e. one of every five college students (19.7\%) were suffering from DEP and/or DER to a remarkable degree. A previous study using the SCID-D yielded $0.8 \%$ for 12 -month prevalence of DSM-IV DEP disorder (women $0.9 \%$, men $0.6 \%$ ) in a sample recruited from the general population in New York State (Johnson, Cohen, Kasen, \& Brook, 2006). One study in Sivas City/Turkey yielded $1.4 \%$ lifetime prevalence for DSM-IV DEP disorder and 1.1\% for DER without DEP among women (Sar ,Akyüz, \& Dogan, 2007); i.e. 2.5\% lifetime prevalence of DSM-5 DEP-DER disorder. The dramatically higher prevalence obtained in the present study was due to the individuals suffering from other specific DDs (e.g. DID and it subthreshold forms) who were also experiencing DEP and/or DER.

Per definition, "distinct personality states" (Putnam, 1997) do not belong to the DSM-5 DEP-DER disorder, however, both DEP and DER are commonly observed in other specific DDs which may involve distinct personality states. Namely, in the present study, of 78 individuals with DDs, 51 (65\%) had either DID or DD not otherwise specified; i.e. they had distinct mental states. For example, in Table 1, the fourth most common symptom on SDEPQ was: "Part doing things while observing part talks about them". In contrast to the claims of the non-dissociative nature of DEP and DER, their widespread presence in DDs, as per the findings of this study, suggests that they may be dissociative phenomena indeed. Additionally, the present study documented associations between DA, and DEP and DER which may also point to the dissociative nature of the latter two. Moreover, even in DEP-DER disorder, "personality" may be divided in subsystems described in the structural dissociation theory as "apparently normal" 
(ANP) and "emotional" (EP) personality parts (Van der Hart, Nijenhuis, \&Steele, 2006). DEP and DER (as well as DA) may occur due to the avoidance between various EP'ies and ANP'ies and constitute negative dissociative symptoms. Alternatively, intrusions between EP'ies and ANP'ies may lead to positive dissociative symptoms (e.g. hallucinations, flashbacks).

To begin from the most severe end of the BPD-and/or DD spectrum; there were significant correlations between all clinical scale and childhood trauma scores and total number of the DSM-IV BPD criteria met (Table 3). BPD criteria represented the severity of the overall psychopathological condition (BPD and/or DD) better than the SCID-D total score. The significant statistical interaction between DD and BPD on SCID-D total score pointed to a relatively severe condition for individuals with "dual diagnosis". While both BPD and DD were associated with significant effects on cognitive-emotional self-detachment (Table 4), "detachment from reality" was a predictor of BPD but not DD. Alongside SCID-D total scores, both SCID-D DER and "detachment from reality" were associated with significant interaction between two diagnoses. Detachment from reality was correlated with BPD criteria as well (Tables 3 and 4). While "detachment from reality" seemed to be an indicator of BPD, clinician assessed DEP was an indicator of DD. At the mildest end of the BPD-DD spectrum, the "DD only" group differed from "controls" only on SCID-D total score. "BPD only", however, differed from controls (but not from "DD only") on SDEPQ and SDERQ (but not on any SCID-D score). Hence, self-report assessment of DEP and DER seemed to be more sensitive than clinician's assessment in detecting BPD whereas the SCID-D total score was more sensitive in detecting DD at the milder end of the spectrum. Hence, overall severity of the clinical condition leads to different sensitivities for the two assessment types.

Participants with BPD may have underreported their experiences of DEP in clinical 
interview or, alternatively, may have overreported DEP in self-report setting. As claimed in an earlier analysis in the context of DA in BPD and/or DDs (Şar, Alioğlu, Akyüz, \& Karabulut, 2014), systematic discrepancies in self-report and clinician-administered assessment may also be related to the psychopathology itself. We speculate that the BPD group (with or without DD) may have omitted particular symptoms spontaneously in the presence of an interviewer. This could be attributable to a number of factors (e.g. feelings of shame, fear of being judged as sick, hard to detect switching between personality states with differing abilities to comply with responses to the questions of the study, and so on . The influence of such fluctuations on awareness has been described by the "perceptual theory of dissociation" (Beere, 1995) as a variant of state-dependent learning processes. Systematic discrepancies in assessment may also be related to different types of childhood adversities and relationship to the perpetrator. In an earlier analysis, BPD was related to all types of childhood abuse and physical neglect but DDs to childhood emotional neglect and denial of childhood trauma (Sar et al., 2006) as shown by the minimization of childhood trauma measure of the CTQ (MacDonald et al., 2016). "Betrayal trauma" (Freyd, 1994) which is inherent to abusive relationships, has been shown to be associated with BPD characteristics (Kaehler and Freyd, 2009).

Neither BPD nor DD had any statistically significant effect on bodily self-detachment and perceptual detachment in variance analysis. Both factors seemed to be related to traumarelated phenomena which did not fit a BPD and/or DD; e.g. Complex PTSD or other conditions which were possibly prevalent in the control group; however, they were not screened as such. Perceptual detachment was associated with SCID-D DEP, clinician-assessed and self-reported DA, and a multimodal childhood trauma history. Constituting a subtler condition both in terms of symptomatology and trauma history, bodily self-detachment was associated with self-reported 
DA and neglect. Hence, bodily detachment may point to an attachment disturbance based on neglect in childhood (Van Dijke and Ford, 2015).

Several types of childhood trauma were not correlated with SCID-D DER but with SCIDD DEP and self-reported DEP and DER. Apparently, SCID-D DER had components which were not trauma-related (e.g. attachment disturbance) or, alternatively, DA led to underreporting of childhood trauma. While self-reported DER was associated both with clinician assessed and selfreported DA in the study, clinician-assessed DER was correlated with clinician assessed DA only. It is possible that the clinician assessed DER was associated with "amnesia to amnesia" (Kluft,1988) which interfered with self-report assessment. Beside SCID-D total score and detachment from reality, the clinician-assessed DER was the only variable which showed a statistically significant interaction between BPD and DD; i.e. pointing to a synergistic effect. "Detachment from reality" seemed to be relatively specific to BPD; whether as a cause or effect (e.g. as DER due to rejection by the social environment by the subsequent to relationships disturbed by emotion dysregulation or insecure attachment) (Van Dijke and Ford, 2015).

The present study has several limitations. Firstly, it is the first and only study using the SDEPQ and SDERQ. Hence, any finding of this study should be considered as preliminary. Second, childhood trauma reports are of retrospective nature and subject to distortion. This distortion may pertain to overreporting as well as underreporting. Considering that the DD group involved individuals with DA as well as those who minimized trauma, underreporting may apply to members of this group in particular. Third, the BPD only group is small $(n=22)$ and includes only seven women. Nevertheless, in the study group overall, male students were more traumatized than females including with respect to childhood sexual abuse (Şar et al., 2006). This may represent a naturalistic sample bias; potentially due to a more severe impairment 
among females in the general population which hinders the achievement of becoming a college student. Last but not least, data were gathered from a non-clinical and highly functional population. DEP and DER were quite common among high-functioning Turkish students; however, the rather low SCID-D scores compared to those of the clinical samples (Kundakci et al., 2014) suggest that their mental disturbance may not be severe. A modest level of dissociation may be normative in Turkey due to widespread exposure to societal stress; e.g. migration, economic instability, cultural change, and last but least, being a constant target to politically motivated terrorism (Dorahy, Lewis, Millar, \& Gee ,2003; Sar and Ozturk, 2013).

\section{Acknowledgements}

The authors thank Pam Stavropoulos, $\mathrm{PhD}$ for her help in editing this manuscript.

\section{REFERENCES}

American Psychiatric Association (2013). Diagnostic and statistical manual of mental disorders, Edition 5. Washington DC: American Psychiatric Association.

Beere, D. (1995). Loss of "background". A perceptual theory of dissociation. DISSOCIATION, 8 (3), 165-174.

Bernstein, D.P., Fink, L., Handelsman, L., Foote, ., Lovejoy, M., Wenzel, K., Sapareto, E., \& Ruggiero, J. (1994). Initial reliability and validity of a new retrospective measure of child abuse and neglect. American Journal of Psychiatry, 151, 1132-1136.

Coskunol, H., Bagdiken, I., Sorias, S., \& Saygili, R. (1994). The reliability of the SCID-IITurkish Version in personality disorders. Turkish Journal of Psychology, 9, 26-29. 
Dorahy, M.J., Lewis, C.A., Millar, R.G., \& Gee T.L. (2003). Predictors of nonpathological dissociation in Northern Ireland: the affects of trauma and exposure to political violence. Journal of Traumatic Stress, 16(6), 611-615.

Dorahy, M.J. \& Van der Hart, O. (2015). DSM-5's posttraumatic stress disorder with dissociative symptoms: challenges and future directions. Journal of Trauma and Dissociation, $16,7-28$.

Edell, W.S., Joy, S.P. , \& Yehuda, R. (1990). Discordance between self-report and observerrated psychopathology in borderline patients. Journal of Personality Disorders, 4(4), 381-390.

Fertuck, E.A., Jekal, A., Song, I. , Wyman, B., Morris, M.C., Wilson, S.T., Brodsky, B.S., \& Stanley, B. (2009). Enhanced 'Reading the Mind in the Eyes' in borderline personality disorder compared to healthy controls. Psychological Medicine, 39(12), 1979-1988.

First, M.B., Gibbon, M., Spitzer, R.L., Williams, J.B., \& Benjamin, L. (1996). Structured Clinical Interview for DSM-IV Axis II Personality Disorders (SCID-II). Washington DC: American Psychiatric Press.

Fischer, G., \& Riedesser, P. (1999). Lehrbuch der Psychotraumatologie (Textbook of Psychotraumathology). München: Ernst Reinhardt Verlag. 
Freyd, J. J. (1994). Betrayal trauma: Traumatic amnesia as an adaptive response to childhood abuse. Ethics \& Behavior, 4(4), 307-329.

Jepsen, E., Langeland, W., \& Heir, T. (2013). Impact of dissociation and interpersonal functioning on inpatient treatment for early sexually abused adults. European Journal of Psychotraumatology, 4. doi:http://dx.doi.org/10.3402/ejpt.v4i0.22825

Johnson ,J.G., Cohen, P., Kasen, S., \& Brook, J.S. (2006). Dissociative disorders among adults in the community, impaired functioning, and axis I and II comorbidity. Journal of Psychiatric Research, 40(2), 131-140.

Kaehler, L. A., \& Freyd, J. J. (2009). Borderline personality disorder: A betrayal trauma approach. Psychological Trauma: Theory, Research, Practice, and Policy, 1(4), 261-268.

Kluft, R. P. (1988). The dissociative disorders. In J. Talbott, R. Hales, \& S. Yudofsky (Eds.), The American Psychiatric Press textbook of psychiatry (pp. 557-585). Washington, DC: American Psychiatric Press.

Kundakci, T., Şar, V., Kiziltan, E., Yargic, L.I., \&Tutkun, H. (2014). The reliability and validity of the Turkish Version of the Structured Clinical Interview for DSM-IV Dissociative Disorders (SCID-D): A preliminary study. Journal of Trauma and Dissociation ,15(1),24-34. 
Lanius, R.A., Vermetten, E., Loewenstein, R.J., Brand, B., Schmahl, C., Bremner, J.D., \& Spiegel, D. (2010). Emotion modulation in PTSD: clinical and neurobiological evidence for a dissociative subtype. American Journal of Psychiatry, 167, 640-647.

MacDonald, K., Thomas, M.,Sciolla, A., Schneider,B., Pappas,K., Bleijenberg,G., ...... ,\& Wingenfeld, K. (2016). Minimization of childhood maltreatment is common and consequential: results from a large, multinational sample using the Childhood Trauma Questionnaire. PLOSeONE 11(1):e0146058. doi: 10.1371/journal.pone.0146058.

Meares, R. (2012).A dissociation model of borderline personality disorder. New York, NY: Norton.

Putnam, F. W. (1997). Dissociation in children and adolescents: A developmental perspective. New York, NY: Guilford Press.

Sar, V. (2011). Developmental trauma, complex PTSD and the current proposal of DSM-5. European Journal of Psychotraumatology, 2, 5662, doi: 10.3402/ejpt.v2i0.5622

Sar, V., Akyüz, G., \& Dogan, O. (2007). Prevalence of dissociative disorders among women in the general population. Psychiatry Research, 149 (1-3), 169-176. 
Sar, V., Akyuz, G., Kugu, N., Ozturk, E., \& Ertem-Vehid, H. (2006). Axis-I dissociative disorder comorbidity of borderline personality disorders and reports of childhood trauma. Journal of Clinical Psychiatry, 67(10), 1583-1590.

Şar, V., Alioğlu, F., Akyüz, G., \& Karabulut, S. (2014). Dissociative amnesia in dissociative disorders and borderline personality disorder: Self-rating assessment in a college population. Journal of Trauma and Dissociation, 15(4), 477-493.

Sar, V., Kundakci, T., Kiziltan, E., Yargic, L.I., Tutkun, H., Bakim, B., Aydiner, O., Ozpulat, T., Keser, V., \& Ozdemir, O. (2003). Axis-I dissociative disorder comorbidity of borderline personality disorder among psychiatric outpatients. Journal of Trauma and Dissociation, 4 (1), 119-136.

Şar, V., \& Ozturk, E. (2013). Stimulus deprivation and overstimulation as dissociogenic agents in postmodern oppressive societies. Journal of Trauma and Dissociation, 14(2), 198-212.

Sar, V., Ozturk, E. , \& İkikardes, E. (2012). Reliability and validity of the Turkish version of the Childhood Trauma Questionnaire (CTQ). Turkiye Klinikleri Tip Bilimleri Dergisi, 32(4), 1054-1063.

Simeon, D., Guralnik, O., Schmeidler, J., Sirof, B.,\& Knutelska, M.(2001). The role of childhood interpersonal trauma in depersonalization disorder. American Journal of Psychiatry, 158, $1027 \cdot 1033$. 
Spiegel, D., Lewis-Fernandez, R., Loewenstein, R., Şar, V., Simeon, D., Vermetten, E., Cardeña, E., Brown, R.J., \& Dell, P.F. (2011). Dissociative disorders in DSM-5. Depression and Anxiety 28(9), 824-852.

Steinberg, M. (1994). Structured Clinical Interview for DSM-IV Dissociative Disorders - Revised (SCID-D-R). Washington DC: American Psychiatric Press.

Steinberg, M., \& Schnall, M. (2000). The stranger in the mirror. New York: Cliff Street Books.

Van der Hart, O., Nijenhuis, E.R.S., \& Steele, K. (2006). The haunted self: structural dissociation and the treatment of chronic traumatization. New York: Norton.

Van Dijke, A., \& Ford, J. D. (2015). Adult attachment and emotion dysregulation in borderline personality and somatoform disorders. Borderline Personality Disorder and Emotion Dysregulation, 2:6 DOI 10.1186/s40479-015-0026-9

Van Dijke, A., van der Hart, O., Ford, J.D., van Son, M., van der Heijden, P., \& Bühring, M. (2010). Affect dysregulation and dissociation in borderline personality disorder and somatoform disorder: differentiating inhibitory and excitatory experiencing states. Journal of Trauma and Dissociation, 11(4),424-443. 
TABLE 1: Mean scores and prevalence of the Steinberg Depersonalization and Derealization Questionnaire items in the overall group $(\mathrm{N}=1301)$

\begin{tabular}{|c|c|c|c|c|}
\hline DEPERSONALIZATION (SDEPQ) & Mean & SD & $\begin{array}{l}>=3 \\
(\%)\end{array}$ & $\begin{array}{l}\text { Also } \\
\text { impaired } \\
(\%)\end{array}$ \\
\hline Feeling spacey & 2.58 & 0.93 & 55.2 & 27.7 \\
\hline Turning off or detaching from emotions. & 2.02 & 0.95 & 34.0 & 18.1 \\
\hline Emotions are not in control. & 1.98 & 0.99 & 31.0 & 18.9 \\
\hline Part doing things while observing part talks about them. & 1.92 & 1.05 & 30.8 & 17.8 \\
\hline One's behavior out of control. & 1.90 & 0.89 & 27.1 & 16.4 \\
\hline Words flow from mouth without being in control. & 1.86 & 0.90 & 24.4 & 15.4 \\
\hline Living in a dream & 1.85 & 0.94 & 24.8 & 15.2 \\
\hline See oneself from a distance & 1.85 & 0.98 & 26.8 & 14.7 \\
\hline Real me far away & 1.70 & 0.94 & 22.2 & 15.4 \\
\hline Stranger to or not recognizing oneself in the mirror. & 1.60 & 0.87 & 16.7 & 12.6 \\
\hline Parts of body disconnected from rest. & 1.31 & 0.66 & 8.3 & 6.2 \\
\hline Whole body or parts of it unreal or foreign. & 1.23 & 0.58 & 5.0 & 4.1 \\
\hline Feeling invisible. & 1.21 & 0.55 & 4.6 & 3.6 \\
\hline Hurt or cut oneself to feel pain or to be real. & 1.20 & 0.54 & 4.8 & 3.6 \\
\hline \multicolumn{5}{|l|}{ DEREALIZATION (SDERQ) } \\
\hline People and places known seem unfamiliar. & 1.67 & 0.84 & 18.8 & 10.1 \\
\hline $\begin{array}{l}\text { Looking at the world through fogged glasses, people or } \\
\text { things unclear or distant. }\end{array}$ & 1.44 & 0.77 & 11.8 & 8.0 \\
\hline Friends,relatives, surroundings strange or unreal. & 1.53 & 0.87 & 15.1 & 9.9 \\
\hline People around were just a dream & 1.50 & 0.82 & 13.9 & 9.4 \\
\hline Things around change in size or shape. & 1.38 & 0.74 & 10.4 & 6.7 \\
\hline Colors change in intensity. & 1.34 & 0.68 & 9.0 & 5.6 \\
\hline People change into someone else & 1.43 & 0.84 & 13.1 & 7.8 \\
\hline Relatives were not really related to oneself. & 1.48 & 0.83 & 12.9 & 8.2 \\
\hline Difficulty recognizing friends, family,or home. & 1.31 & 0.68 & 8.9 & 5.7 \\
\hline Puzzled about what is real and unreal around oneself. & 1.61 & 0.88 & 17.1 & 7.7 \\
\hline People and places known fade away or disappear & 1.35 & 0.70 & 9.2 & 6.6 \\
\hline Detachment from other people & 1.95 & 1.00 & 31.2 & 1.8 \\
\hline
\end{tabular}


TABLE 2: Principal component analysis (varimax rotation) on Steinberg Depersonalization and Derealization Questionnaire items $(\mathrm{n}=191)$

\begin{tabular}{|c|c|c|c|c|}
\hline & $\begin{array}{l}\text { Cognitive- } \\
\text { emotional } \\
\text { Self- } \\
\text { Detachmen } \\
\text { t }\end{array}$ & $\begin{array}{l}\text { Perceptua } \\
1 \\
\text { Detachme } \\
\text { nt }\end{array}$ & $\begin{array}{l}\text { Detachme } \\
\text { nt from } \\
\text { reality }\end{array}$ & $\begin{array}{l}\text { Bodily } \\
\text { Self- } \\
\text { Detachm } \\
\text { ent }\end{array}$ \\
\hline Real me far away & .72 & .18 & .20 & .25 \\
\hline See oneself from a distance & .71 & .02 & .01 & .26 \\
\hline Part does things while observing part talks about them & .66 & .18 & .15 & .20 \\
\hline Feeling spacey & .65 & .27 & .31 & .03 \\
\hline Detachment from other people. & .65 & .32 & .33 & -.09 \\
\hline One's behavior out of control. & .59 & .31 & .20 & .08 \\
\hline Stranger to or not recognizing oneself in the mirror & .59 & .28 & .17 & .43 \\
\hline Turning off or detaching from emotions & .58 & .27 & -.03 & .14 \\
\hline Living in a dream & .54 & .06 & .24 & .37 \\
\hline Emotions are not in control. & .51 & .34 & .26 & .12 \\
\hline Words flow from mouth without being in control. & .48 & .30 & .33 & .19 \\
\hline Things around change in size or shape. & .13 & .79 & .15 & .19 \\
\hline Colors change in intensity. & .10 & .78 & .08 & .10 \\
\hline People and places known fade away or disappear. & .33 & .68 & .34 & .17 \\
\hline People change into someone else. & .28 & .67 & .08 & .08 \\
\hline Puzzled about what is real and unreal around oneself. & .44 & .63 & .23 & .18 \\
\hline Relatives were not really related to oneself. & .29 & .50 & .49 & .21 \\
\hline Difficulty recognizing friends, family,or home. & .30 & .48 & .21 & .25 \\
\hline Friends, relatives, surroundings strange or unreal. & .32 & .33 & .70 & .21 \\
\hline Hurt or cut oneself to feel pain or to be real. & -.03 & -.10 & .64 & .38 \\
\hline $\begin{array}{l}\text { Looking at the world through fogged glasses, people } \\
\text { or things unclear or distant. }\end{array}$ & .34 & .46 & .59 & .13 \\
\hline People and places known seem unfamiliar. & .41 & .33 & .57 & .04 \\
\hline People around were just a dream. & .33 & .47 & .54 & .28 \\
\hline Whole body or parts of it unreal or foreign. & .25 & .17 & .24 & .79 \\
\hline Feeling invisible. & .25 & .19 & .29 & .68 \\
\hline Parts of body disconnected from rest. & .22 & .43 & .04 & .66 \\
\hline Variance explained & $44.5 \%$ & $6.2 \%$ & $5.4 \%$ & $4.1 \%$ \\
\hline
\end{tabular}


TABLE 3: Spearman correlation coefficients (rho) between clinical scale scores and childhood trauma reports $(n=191)$

\begin{tabular}{|c|c|c|c|c|c|c|c|c|c|c|}
\hline & $\begin{array}{l}\text { SCID- } \\
\text { D TOT }\end{array}$ & $\begin{array}{l}\text { SCID- } \\
\text { D DEP }\end{array}$ & $\begin{array}{l}\text { SCID- } \\
\text { D DER }\end{array}$ & SDEPQ & SDERQ & $\begin{array}{l}\text { Cognitive } \\
\text { Emotional } \\
\text { Self- } \\
\text { detachment }\end{array}$ & $\begin{array}{l}\text { Perceptual } \\
\text { Detachme } \\
\text { nt }\end{array}$ & $\begin{array}{l}\text { Detachment } \\
\text { from Reality }\end{array}$ & $\begin{array}{l}\text { Bodily } \\
\text { Self- } \\
\text { detachme } \\
\text { nt }\end{array}$ & BPD \\
\hline $\begin{array}{l}\text { SCID-D } \\
\text { TOT }\end{array}$ & -- & -- & -- & $.48 * *$ & $.47 * *$ & $.36^{* *}$ & .14 & $.30 * *$ & .05 & -- \\
\hline $\begin{array}{l}\text { SCID-D } \\
\text { DEP }\end{array}$ & $.82 * *$ & -- & $.52 * *$ & $.41 * *$ & $.46^{* *}$ & $.31 * *$ & $.17^{*}$ & $.33 * *$ & .01 & $.45^{* *}$ \\
\hline $\begin{array}{l}\text { SCID-D } \\
\text { DER }\end{array}$ & $.55^{* *}$ & $.52 * *$ & -- & $.28 * *$ & $.31 * *$ & $.22 * *$ & .07 & $.22 * *$ & .05 & $.36 * *$ \\
\hline $\begin{array}{l}\text { SCID-D } \\
\text { DA }\end{array}$ & $.81 * *$ & $.36 * *$ & $.36 * *$ & $.51 * *$ & $.35^{* *}$ & $.24 * *$ & $.18^{*}$ & $.18^{*}$ & .04 & $.46^{* *}$ \\
\hline SDAQ & $.32 * *$ & $.27 * *$ & .13 & $.68 * *$ & $.59 * *$ & $.48 * *$ & $.26^{* *}$ & $.25^{* *}$ & $.22 * *$ & $.44 * *$ \\
\hline Ctq-total & $.22 * *$ & $.21 * *$ & .12 & $.38 * *$ & $.42 * *$ & $.22 * *$ & $.24 * *$ & $.22 * *$ & $.15^{*}$ & $.37 * *$ \\
\hline $\begin{array}{l}\text { Physical } \\
\text { Abuse }\end{array}$ & $.24 * *$ & $.20 * *$ & .12 & $.25 * *$ & $.25 * *$ & $.15^{*}$ & .08 & $.18^{*}$ & .09 & $.27 * *$ \\
\hline $\begin{array}{l}\text { Emotion } \\
\text { al abuse }\end{array}$ & $.31 * *$ & $.33 * *$ & $.15^{*}$ & $.38 * *$ & $.42 * *$ & $.26 * *$ & $.18^{*}$ & $.27 * *$ & .06 & $.41 * *$ \\
\hline $\begin{array}{l}\text { Physical } \\
\text { neglect }\end{array}$ & $.23 * *$ & $.22 * *$ & .16 & $.36^{* *}$ & $.38 * *$ & $.20 * *$ & $.18^{*}$ & $.23 * *$ & $.17 *$ & $.30 * *$ \\
\hline $\begin{array}{l}\text { Emotion } \\
\text { al } \\
\text { neglect }\end{array}$ & .13 & .14 & .03 & $.28 * *$ & $.29 * *$ & $.17^{*}$ & $.17 *$ & .10 & $.15^{*}$ & $.25 * *$ \\
\hline $\begin{array}{l}\text { Sexual } \\
\text { abuse }\end{array}$ & $.17 *$ & .07 & .13 & $.23 * *$ & $.24 * *$ & $.27 * *$ & $.18^{*}$ & .12 & -.06 & $.27 * *$ \\
\hline $\begin{array}{l}\text { Minimiz } \\
\text { ation }\end{array}$ & $-.24 * *$ & $-.23 *$ & -.09 & $-.15^{*}$ & $-.15^{*}$ & $-.16^{*}$ & -.06 & -.07 & -.01 & -.13 \\
\hline BPD & $.56 * *$ & $.45^{* *}$ & $.36 * *$ & $.50 * *$ & $.52 * *$ & $.33 * *$ & $.16^{*}$ & $.41 * *$ & .07 & -- \\
\hline
\end{tabular}

$* \mathrm{p}<.05 \quad * * \mathrm{p}<.001$ 
TABLE 4: A comparison between participants according to their dissociative disorder (DD) and borderline personality disorder (BPD) status (Kruskal-Wallis Variance Analysis)

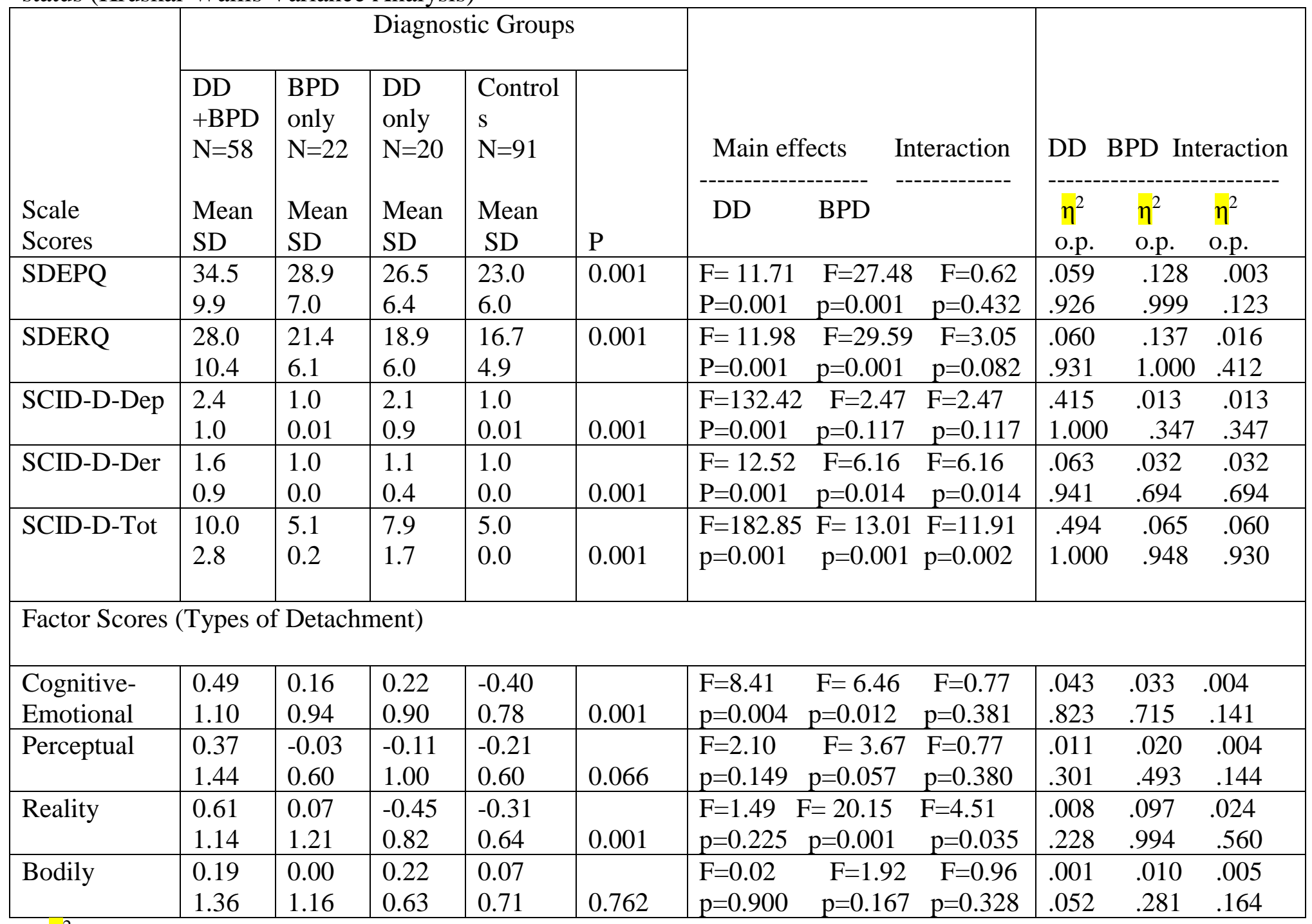

$\eta^{2}=$ Partial eta , o.p. $=$ Observed power 